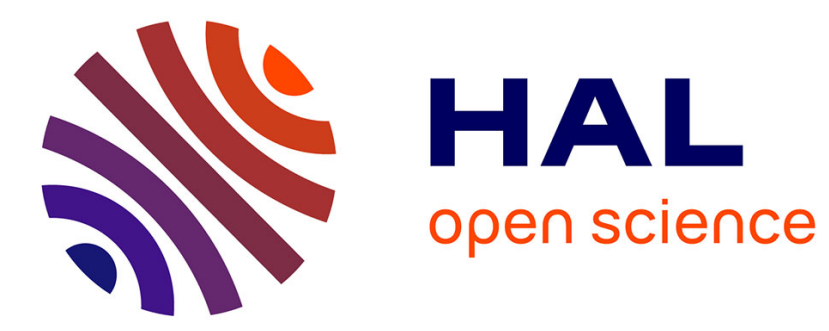

\title{
High-performance copper selenide thermoelectric thin films for flexible thermoelectric application
}

\author{
X.-L. Huang, D.-W. Ao, T.-B. Chen, Y.-X. Chen, F. Li, S. Chen, G.-X. Liang,
} Xianghua Zhang, Z.-H. Zheng, P. Fan

\section{- To cite this version:}

X.-L. Huang, D.-W. Ao, T.-B. Chen, Y.-X. Chen, F. Li, et al.. High-performance copper selenide thermoelectric thin films for flexible thermoelectric application. Materials today energy, 2021, 21, pp.100743. 10.1016/j.mtener.2021.100743 . hal-03249687

\section{HAL Id: hal-03249687 \\ https://hal.science/hal-03249687}

Submitted on 10 Jun 2021

HAL is a multi-disciplinary open access archive for the deposit and dissemination of scientific research documents, whether they are published or not. The documents may come from teaching and research institutions in France or abroad, or from public or private research centers.
L'archive ouverte pluridisciplinaire HAL, est destinée au dépôt et à la diffusion de documents scientifiques de niveau recherche, publiés ou non, émanant des établissements d'enseignement et de recherche français ou étrangers, des laboratoires publics ou privés. 


\section{Credit Author Statement}

Xiao-lan Huang: Methodology, Data curation, Investigation. Dong-wei Ao: Investigation, Writing- Original draft preparation. Tian-bao Chen: Visualization, Investigation. Yue-xing Chen: Formal analysis. Fu Li: Resources. Shuo Chen: Validation. Guang-xing Liang: Formal analysis, Resources. Xiang-hua Zhang: Writing- Reviewing and Editing. Zhuang-hao Zheng: Conceptualization, Supervision, Writing - Review \& Editing. Ping Fan: Supervision. 


\section{Graphical Abstract}

The well-crystallized $\mathrm{Cu}_{2} \mathrm{Se}$ thermoelectric thin films have been synthesized by an efficient layer-by-layer combination reaction method, and the high power factor of 5.3 $\mu \mathrm{Wcm}^{-1} \mathrm{~K}^{-2}$ and $Z T$ value of 0.35 with low thermal conductivity are achieved at room-temperature by optimizing the composition.

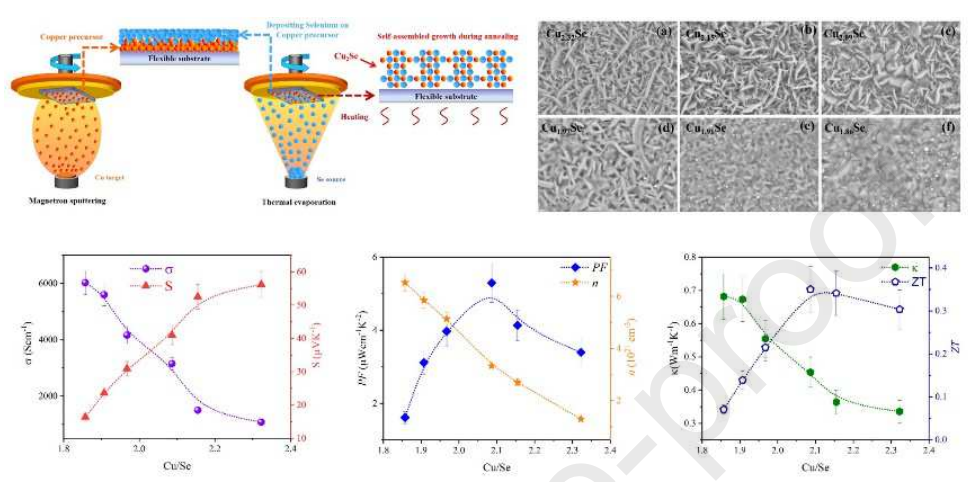




\section{High-performance copper selenide thermoelectric thin films for flexible thermoelectric application}

Xiao-lan Huang ${ }^{\text {a }}$, Dong-wei Ao ${ }^{\text {a }}$, Tian-bao Chen ${ }^{\text {a, b }}$, Yue-xing $\mathrm{Chen}^{\mathrm{a}}, \mathrm{Fu} \mathrm{Li}^{\text {a }}$, Shuo Chen ${ }^{\text {a }}$, Guang-xing Liang ${ }^{\text {a }}$, Xiang-hua Zhang ${ }^{\text {b }}$, Zhuang-hao Zheng ${ }^{\text {a, }}$, Ping Fan ${ }^{\text {a }}$

a Shenzhen Key Laboratory of Advanced Thin Films and Applications, Key Laboratory of Optoelectronic Devices and Systems of Ministry of Education and Guangdong Province, College of Physics and Optoelectronic Engineering, Shenzhen University, Shenzhen 518060, P. R. China; b Univ Rennes, CNRS, ISCR (Institut des Sciences Chimiques de Rennes) UMR6226, Rennes F-35000, France.

*Corresponding author. E-mail: zhengzh@szu.edu.cn

Abstract: Flexible thermoelectric (TE) materials have wide application in fabricating portable/wearable devices due to the advantages of being bendable, small-size and light-weight. Inorganic based flexible thin films have attracted much attention due to their high TE performance. So far, developing high TE properties and environment friendly flexible thin films for practical applications are still a considerable challenge. Copper selenide $\left(\mathrm{Cu}_{2} \mathrm{Se}\right)$ is a non-toxic and low-cost material, providing relatively safe TE modules for thin film devices. In this work, $\mathrm{Cu}_{2} \mathrm{Se}$ based thin films with single crystal phase have been fabricated successfully at flexible substrate by an efficient layer-by-layer combination reaction method. By optimizing the composition, high power factor of $5.3 \mu \mathrm{Wcm}^{-1} \mathrm{~K}^{-2}$ and $Z T$ value of 0.35 with low thermal conductivity are achieved at room-temperature. By bending tests, it is revealing that the prepared thin films possess well flexibility and the designed flexible device 
displays stable out-put power that demonstrate the potential of inorganic thermoelectric materials to be mountable on flexible/wearable substrates for energy harvesting and management devices.

Keywords: Thermoelectric materials; Thin film; $\mathrm{Cu}_{2} \mathrm{Se}$; Flexible

\section{Introduction}

Thermoelectric conversion is a solid-state, secure, convenient and environment friendly energy conversion technology allowing the direct conversion of heat into electricity and vice versa, which has broad applications in cooling, power generation, and waste heat recovery. ${ }^{[1-4]}$ The TE performance of thermoelectric materials is evaluated by the dimensionless figure of merit $(Z T), Z T=S^{2} \sigma \mathrm{T} \kappa^{-1}$, where $S$ is the Seebeck coefficient, $\sigma$ is the electrical conductivity, $\kappa$ is the thermal conductivity, and $\mathrm{T}$ is the absolute temperature. Besides, $S^{2} \sigma$ is called as power factor $(P F)$, which is used to estimate the electronic properties. ${ }^{[5]}$ Recently, the explosive growth of portable and wearable microelectronics has stimulated the development of flexible thermoelectric materials promising for the applications in wearable devices as the self-power generator from the temperature difference between the skin and the ambient environment. ${ }^{[6]}$ Therefore, fabricating high performance flexible TE materials have received great attention and significant work has been reported in the recent years. ${ }^{[7-12]}$ Due to the high performance of inorganic materials, research on depositing inorganic materials on flexible substrates such as fibers, organics, and carbon nanotubes have been widely reported. ${ }^{[13-17]}$ Until now, most of the flexible thin films and devices were fabricated based on the classic Te-based materials because of their 
excellent TE properties. ${ }^{[18-19]}$ However, Te-based materials remain a significant challenge for large-scale commercialization due to the presence of less earth-abundant, toxic, and costly elements. Thus, developing low-cost and nontoxic TE thin films with acceptable performance to substitute Te-based materials is highly desired.

Recently, transition metal selenium compound semiconductor materials [20-24], especially the copper selenide $\left(\mathrm{Cu}_{2} \mathrm{Se}\right)^{[25]}$, have attracted great attention for thermoelectrics. Nontoxic $\mathrm{Cu}_{2} \mathrm{Se}$ has excellent thermoelectric properties that a relatively large $Z T$ value over 2.0 has already been achieved ${ }^{[26]}$, making it extremely promising as a potential alternative for the traditional Te-based materials. Thus, fabricating high-performance $\mathrm{Cu}_{2} \mathrm{Se}$ thin films have also been widely studied and various methods, including solution ${ }^{[27-28]}$, electrodeposition ${ }^{[29]}$, pulsed laser deposition ${ }^{[30]}$, ion beam sputtering deposition ${ }^{[31]}$, reactive evaporation ${ }^{[32]}$, galvanic deposition $^{[33]}$, and pulsed/magnetron sputtering reactive ${ }^{[34]}$, have been used. For instance, Lin et al. used solution method to prepare $\mathrm{Cu}_{2} \mathrm{Se}$ based thin film, resulting maximum $P F$ of $4.6 \mu \mathrm{Wcm}^{-1} \mathrm{~K}^{-2}$ on the flexible polyimide substrate, respectively. ${ }^{[27]}$ Scimeca et al. optimized the carrier concentration of $\mathrm{Cu}_{2} \mathrm{Se}$ based thin films to significantly improve their TE properties through a soaking process in $\mathrm{Cu}^{+}$ion solution. ${ }^{[28]}$ However, the reported $\mathrm{Cu}_{2} \mathrm{Se}$ thin films to date usually exhibit much lower TE properties than that of the bulk $\mathrm{Cu}_{2} \mathrm{Se}$.

Magnetron sputtering and thermal evaporation methods are commonly used to prepare thin films, especially for substances which are extremely susceptible to oxidation. Based on the advantages of these two technologies, it is expected to produce 
high-performance $\mathrm{Cu}_{2} \mathrm{Se}$ thin films by using magnetron or evaporation method. However, some unavoidable issues limit the use of these two technologies, i.e. Se has much high saturated vapor pressure and cannot be efficiently controllable during the sputtering process; $\mathrm{Cu}$ is difficult to evaporate because of its high boiling point. Therefore, there are only a few reports about $\mathrm{Cu}_{2} \mathrm{Se}$ thin films prepared by magnetron or evaporation. In this work, an efficient layer-by-layer combination reaction method by integrating the magnetron sputtering and thermal evaporation technology is developed to prepare flexible $\mathrm{Cu}_{2} \mathrm{Se}$ thin films. The effect of composition content on the microstructure and thermoelectric properties of the flexible $\mathrm{Cu}_{2} \mathrm{Se}$ thin films were systematically investigated.

\section{Experimental Section}

The process of the $\mathrm{Cu}_{2} \mathrm{Se}$ based thin film fabrication is represented by schematic diagram in Fig. 1. At first, $\mathrm{Cu}$ precursor layer was sputtered by using magnetron sputtering deposition method and the flexible Kapton polyimide film (200HN) are used as the substrate which can be used at the temperatures up to $200{ }^{\circ} \mathrm{C}$. The sputtering power, background pressure and working pressure were kept at $15 \mathrm{~W}$, $8 \times 10^{-4} \mathrm{~Pa}$ and $1.6 \mathrm{~Pa}$, respectively. The $\mathrm{Cu}$ layer is controlled to be $100 \mathrm{~nm}$ with the sputtering rate of $1 \mathrm{As}^{-1}$. After completing the $\mathrm{Cu}$ deposition, the Se layer was continued to deposit on the $\mathrm{Cu}$ precursor layer by using thermal evaporation deposition method at another deposition system. The working current of the evaporation source was $60 \mathrm{~A}$ with the background pressure of $5.0 \times 10^{-4} \mathrm{~Pa}$. The average deposition rate of Se is $\sim 0.8 \AA \mathrm{s}^{-1}$, which was controlled using a quartz 
microbalance, and the thickness of Se layer is varied from $70 \mathrm{~nm}$ to $120 \mathrm{~nm}$. Finally, all the thin films with different Se contents were annealed at $200 \square$ for one hour using a heating system in a glove box under nitrogen atmosphere.

Crystal structure of the thin films are analyzed by X-ray diffraction (XRD, Ultima-iv) with the $2 \theta$ angle range from $10^{\circ}$ to $70^{\circ}$, using $\mathrm{CuK}_{\alpha}$ radiation (under operation requirements of $40 \mathrm{~mA}$ and $40 \mathrm{kV}$ ). Surface topography of the $\mathrm{Cu}_{2} \mathrm{Se}$ based thin film are investigated using a scanning electron microscope (SEM, Supra 55) with an electron beam accelerated of $5 \mathrm{kV}$. Composition is investigated by using an energy dispersive X-ray spectroscope (EDS, Bruker Quantax 200) equipped with the SEM. Transmission electron microscopy (TEM, JEM-3200FS) is used to measure the micro-structure of the thin films. The chemical valence was characterized by conducting X-ray photoelectron spectroscopy (XPS, Escalab 250Xi) with a monochrome $\mathrm{Al} \mathrm{K}_{\alpha} \mathrm{X}$-ray source of $1486.6 \mathrm{eV}$. Before test, samples were plasma etched for 30 seconds to remove impurities on the surface of the thin film. The total thickness of the thin films was measured by a Dektak3 ST surface-profile measurement system and shown in Table S1 (Supporting information). The mobility and carrier density are investigated by Van der Pauw Hall measurement (HL5500PC, Nanometrics). In-plane electrical conductivity and Seebeck coefficient are measured by the Seebeck-conductivity coefficient measurement system (SBA458, Netzsch). Thermal conductivity at room temperature is determined by a transient hot-wire theory method (TC3000, Xiatech). The current-voltage (I-V) curves of the thermoelectric device of thin films are measured by a Keithley 2400. 


\section{Results and analysis}

The composition content of the $\mathrm{Cu}$-Se thin films was analyzed by EDS as shown in Table 1. The $\mathrm{Cu}$ : Se atomic ratio is close to 2:1 when the Se layer thickness is $100 \mathrm{~nm}$, and show slightly $\mathrm{Cu}$-excess and Se-excess when the Se thickness is less than and higher than $100 \mathrm{~nm}$, respectively. For better discussion, the prepared $\mathrm{Cu}-\mathrm{Se}$ thin films are named as $\mathrm{Cu}_{2.32} \mathrm{Se}, \mathrm{Cu}_{2.15} \mathrm{Se}, \mathrm{Cu}_{2.09} \mathrm{Se}, \mathrm{Cu}_{1.97} \mathrm{Se}, \mathrm{Cu}_{1.91} \mathrm{Se}$ and $\mathrm{Cu}_{1.86} \mathrm{Se}$, corresponding to the $\mathrm{Cu}$ atomic ratio in the thin films. Figure 2 shows the phase structural of the thin films with different $\mathrm{Cu}$ content measured by XRD. After comparing to the XRD pattern (PDF\#37-1187) of the powder $\mathrm{Cu}_{2} \mathrm{Se}$, it confirms that all the diffraction peaks of the samples belong to the cubic structure of $\mathrm{Cu}_{2} \mathrm{Se}$ without impurity peaks, suggesting that the samples have well-crystallinity with single $\mathrm{Cu}_{2} \mathrm{Se}$ phase. Moreover, according to the Debye-Sheerer equation ${ }^{[35]}$, the estimated grain size of the thin films (Fig. S1, supporting information) calculated using the XRD data is around $25 \mathrm{~nm}$, indicating the nano-crystallinity of the samples. The binding states of $\mathrm{Cu}$ and $\mathrm{Se}$ in the $\mathrm{Cu}_{2.09} \mathrm{Se}$ and $\mathrm{Cu}_{1.97} \mathrm{Se}$ samples are investigated by XPS. As shown in Fig. 3(a), the core level spectrum of $\mathrm{Cu}_{2.09} \mathrm{Se}$ sample reveals that two strong peaks are obtained at $\sim 933 \mathrm{eV}$ of $\mathrm{Cu} 2 \mathrm{p}_{3 / 2}$ and $\sim 953 \mathrm{eV}$ of $\mathrm{Cu} 2 \mathrm{p}_{1 / 2}$, which are well matched with the spin-orbit phenomena of compound state of $\mathrm{Cu}$ (I). Similar observation for $\mathrm{Cu}$ of $\mathrm{Cu}_{1.97} \mathrm{Se}$ sample is obtained. Thus, the results suggest that both the $\mathrm{Cu}$-excess and $\mathrm{Cu}$-deficiency samples have stable $\mathrm{Cu}^{1+}$ state ${ }^{[36]}$. A broad peak ranging from 53-57 eV is observed from the samples as shown in Fig. 3(b). It can be identified into two symmetric peaks to Se $3 \mathrm{~d}_{5 / 2}$ and $\mathrm{Se} 3 \mathrm{~d}_{3 / 2}$ respectively located at $54.5 \mathrm{eV}$ and 55.7 
$\mathrm{eV}$, which is the characteristic shape of compound Se (-II) in a consistent bonding environment. ${ }^{[36]}$ Additionally, no high-valence copper or selenium related to oxidation state can be observed from the XPS patterns, which can be attribute to the fact that the thin film is prepared in a vacuum and heat treated is also carried in a low-oxygen environment. Combining the XRD and EDS results, it can be concluded that the prepared $\mathrm{Cu}_{2} \mathrm{Se}$ thin films have few defects and well-crystallinity, which is beneficial to obtain high TE performance.

The surface morphology of the samples is shown in Fig. 4. Nano-sheet-liked particles are observed on the surface of the Cu-excess samples as shown in Fig. 4 (a), (b) and (c), indicating the flake structure of the thin films. The length of the nano-particles decreases with the decrease of $\mathrm{Cu}$ content, while the width increases. Interestingly, compact particles without obvious shape structure are obtained from the $\mathrm{Cu}_{1.91} \mathrm{Se}$ and $\mathrm{Cu}_{1.86}$ Se samples. As shown from the XRD results that the peak intensity increases and some addition peaks are observed after change the composition ratio, indicating the change of thin film growth structure. Thus, such difference of morphology is anticipated due to the different stacked growth of the grains at different composition ratio. High-resolution TEM (HRTEM) analysis of the sample are performed to further investigate the microstructure of the thin films. Figure 5(a) displays the energy dispersive X-ray spectroscope mapping images of the $\mathrm{Cu}_{1.97} \mathrm{Se}$ sample and indicates that the $\mathrm{Cu}$ and Se have uniform distribution. Figure 5(b) shows the high-resolution TEM image and the measured lattice spacing is $3.42 \AA$, which correspond to the (060) plane of the $\mathrm{Cu}_{2} \mathrm{Se}$. The $\mathrm{Cu}_{2.09} \mathrm{Se}$ sample also displays uniform distribution of the $\mathrm{Cu}$ 
and Se as shown in Fig. 5(c). Figure 5(d) displays that crystalline nanoparticles stack compactly with each other, and the measured lattice spacing is $3.42 \AA$, which correspond to the (060) plane of the $\mathrm{Cu}_{2} \mathrm{Se}$, suggesting the well-crystallinity of the sample. Interestingly, no $\mathrm{Cu}$ related crystal clusters are observed from the mapping image which is agreed with the XPS and XRD results. In general case, the ex-excess $\mathrm{Cu}$ might as the liquid-liked state and exists in the crystal grain's ${ }^{[37]}$ which can also be seen in the Fig. 5(d).

The room-temperature electrical conductivity $\sigma$ and Seebeck coefficient $S$ are shown in Fig. 6(a). With the increase of $\mathrm{Cu}$ content, the $\sigma$ decreases, which is attributed to the decrease of carrier concentration as shown in Fig. 6(b). Conversely, the mobility (Table S2, supporting information) increases when the $\mathrm{Cu}$ content increases, that benefits to obtain high $S$ coefficient, and the maximum value can be achieved to be over $55 \mu \mathrm{VK}^{-1}$. Power factor of the samples are calculated and shown in Fig. 6(b). It increases firstly, and reaches to a maximum value of $5.3 \mu \mathrm{Wcm}^{-1} \mathrm{~K}^{-2}$ from the $\mathrm{Cu}_{2.09} \mathrm{Se}$ sample, then decreases when the $\mathrm{Cu}$ content continued to raise. Nevertheless, the achieved maximum power factor can be compared to one of the highest values of flexible $\mathrm{Cu}_{2} \mathrm{Se}$ thin films prepared by other method. ${ }^{[38]}$ The in-plane thermal conductivity of samples is shown in Fig. 6(c) and displays the decreasing trend with the increasing $\mathrm{Cu}$ content. Interestingly, the excess-Cu samples have low thermal conductivity $\kappa$. Based on the micro-structure results as mentioned above, it can be attributed as the nano-structure of the thin films, that scatter the mid- and long- length phonons more efficiently. The estimated $Z T$ in Fig. 6(c) demonstrates that the 
$\mathrm{Cu}$-excess samples have higher values than that of the Se-excess samples due to the higher $S$ and lower $\kappa$. The maximum $Z T$ of 0.35 is achieved from the $\mathrm{Cu}_{2.09} \mathrm{Se}$ sample which is close to the highest value at room-temperature of the bulk $\mathrm{Cu}_{2} \mathrm{Se}$ materials, [39-41] indicating the effectiveness of this innovative technique for preparing high-performance flexible $\mathrm{Cu}_{2} \mathrm{Se} \mathrm{TE}$ thin film.

The mechanical property of the flexible thin film is measured by a bending resistance system of which the schematic diagram and optical image are shown in Fig. 7(a) and (b). The relative resistance change $\left(\Delta R / \mathrm{R}_{0}=\left(R^{\prime}-\mathrm{R}_{0}\right) / \mathrm{R}_{0}\right)$ was applied to quantitatively investigate the mechanical stability of the thin films, where $\mathrm{R}_{0}, R^{\prime}$ and $\Delta R$ were the original resistance, bending resistance and difference between $R^{\prime}$ and $\mathrm{R}_{0}$, respectively. ${ }^{[42]}$ The influence of bending radius $(3.2 \mathrm{~mm}, 3.8 \mathrm{~mm}, 4.1 \mathrm{~mm}, 4.8 \mathrm{~mm}$, $5.3 \mathrm{~mm}, 5.8 \mathrm{~mm}, 6.2 \mathrm{~mm}, 6.5 \mathrm{~mm})$ as well as the bending cycles $(200,400,600,800)$ on the $\Delta R / \mathrm{R}_{0}$ of the flexible thin films are shown in Fig. 7(c). It can be seen that the $\Delta R / \mathrm{R}_{0}$ is slightly increased with the increase of bending radius and bending cycles. The maximum difference of $\Delta R / \mathrm{R}_{0}$ is about $3 \%$ when the bending cycles increased to be 800 with the radius of $6.5 \mathrm{~mm}$, which is close to the value reported from the literatures ${ }^{[43]}$, suggesting that the thin film has well flexible properties.

In order to show the potential energy-harvesting applications of the present copper selenide thin film for wearable electronic devices, a simple TE device is fabricated. The structure diagram and optical image of the fabricated device are shown in Fig. 7(d) and (e). The device consists of 10 pieces of the thin film and all legs were connected in series by painting silver paste. Figure 7(f) shows the current-voltage $(I-V)$ 
curves and current-power $(I-P)$ curves of the device at different temperature difference $\left(\Delta \mathrm{T}=\mathrm{T}_{\text {hot }}-\mathrm{T}_{\text {cold }}\right)$. As shown in Fig. $7(\mathrm{f})$, the open circuit voltage $\left(U_{o c}\right)$ was $0.96 \mathrm{mV}, 1.09 \mathrm{mV}, 2.01 \mathrm{mV}$, and $3.84 \mathrm{mV}$ corresponding to $\Delta \mathrm{T}=23 \square, 28 \square, 33 \square$ and $38 \square$, respectively. The measured $U_{o c}$ s are basically consistent with the results that were calculated using the Seebeck effect.

The output power $P$ is calculated by the equation as follows: ${ }^{[44]}$

$$
P=I^{2} \mathrm{R}_{\text {load }}=\left(\frac{U_{o c}}{\mathrm{R}_{\text {in }}+\mathrm{R}_{\text {load }}}\right)^{2} \mathrm{R}_{\text {load }}
$$

Where $I, \mathrm{R}_{\text {load }}$ and $\mathrm{R}_{\text {in }}$ are output current, the external resistance and the internal resistance respectively. In addition, the power density $\left(P_{D}\right)$ is calculated by the following equation: ${ }^{[44]}$

$$
P_{D}=\frac{P_{\max }}{N \cdot A}=\frac{P_{\max }}{N \cdot w \cdot t}
$$

Where $N, A, w$, and $t$ is the number of the legs, the cross-sectional area of the leg, the width of the leg, the thickness of the thin film, respectively. As shown in Fig. 3(f), the output power has the highest value $3.31 \mathrm{nW}$ when the output current was $1.84 \mu \mathrm{A}$ under the temperature difference of $38 \square$. When $\Delta \mathrm{T}=23 \square, 28 \square, 33 \square$ and $38 \square$, the calculated maximum $P_{D}$ was $56.14 \mathrm{mWm}^{-2}, 75.43 \mathrm{mWm}^{-2}, 226.32 \mathrm{mWm}^{-2}$ and $580.70 \mathrm{mWm}^{-2}$, respectively. The maximum $P_{D}$ is comparable with that of some previous reports ${ }^{[45-47]}$.

\section{Conclusions}

In this work, flexible $\mathrm{Cu}_{2} \mathrm{Se}$ thin films with various atomic ratios were prepared by using a simple layer-by-layer combination reaction method. The self-assembled 
growth of single $\alpha$-phase $\mathrm{Cu}_{2} \mathrm{Se}$ thin films is successfully realized after annealing. Although the electrical conductivity decreases with an increase of $\mathrm{Cu}$ content but a significant increase in the Seebeck coefficient is observed due to the decrease of carrier concentration. It is observed that the $\mathrm{Cu}$-excess thin films exhibit low thermal conductivity, which is attributed to the nano-plate-liked structure and ultimately high $Z T$ of 0.35 with well flexibility $\mathrm{Cu}_{2} \mathrm{Se}$ thin film is achieved at room temperature. Additionally, the prepared thin film exhibits good flexibility with about $97 \%$ of the original electrical conductivity retention after 800 bending cycles and the fabricated device has stable output power with the maximum power density of $580.70 \mathrm{mWm}^{-2}$. Therefore, the competitive performance of the devices reported in this work has the potential for portable/wearable electronic applications in the field of thermoelectric devices.

\section{Acknowledgements}

X. L. Huang and D. W. Ao contributed equally. This work was supported by the National Natural Science Foundation of China (Grant No. 11604212), Guangdong Basic and Applied Basic Research Foundation (2020A1515010515), Shenzhen Key Lab Fund (ZDSYS 20170228105421966), the European Union through the European Regional Development Fund (ERDF), the Ministry of Higher Education and Research, the French region of Brittany and Rennes Metropole. The authors are also thankful for the assistance on STEM-HAADF observation received from the Electron Microscope Center of the Shenzhen University.

\section{References}


[1] P. F. Qiu, X. Shi, L. D. Chen, Cu-based thermoelectric materials, Energy Storage Mater., 2016, $3,8$.

[2] J. He, T. M. Tritt, Advances in thermoelectric materials research: Looking back and moving forward, Science, 2017, 357, 6358.

[3] M. Zebarjadi, K. Esfarjani, M. S. Dresselhaus, Z. F. Ren, G. Chen, Perspectives on thermoelectrics: From fundamentals to device applications, Energy Environ. Sci., 2012, 5, 5147.

[4] W. D. Liu, Y. Yu, M. Dargusch, Q. Liu, Z. G. Chen, Carbon allotrope hybrids advance thermoelectric development and applications, Renew Sust. Energ. Rev., 2021, 414, 110800.

[5] Z. H. Zheng, X. L. Shi, D. W. Ao, W. D. Liu, Y. X. Chen, F. Li, S. Chen, X. Q. Tian, X. R. Li, J. Y. Duan, H. L. Ma, X. H. Zhang, G. X. Liang, P. Fan, Z. G. Chen, Rational band engineering and structural manipulations inducing high thermoelectric performance in n-type $\mathrm{CoSb}_{3}$ thin films, Nano Energy, 2021, 81, 105683.

[6] X. L. Shi, W. Y. Chen, T. Zhang, J. Zou, Z. G. Chen, Fiber-based thermoelectrics for solid, portable, and wearable electronics, Energy Environ. Sci., 2021,14, 729.

[7] L. Wang, Z. Zhang, Y. Liu, B. Wang, L. Fang, J. Qiu, K. Zhang, S. Wang, Exceptional thermoelectric properties of flexible organic-inorganic hybrids with monodispersed and periodic nanophase, Nat. Commun., 2018, 9, 3817.

[8] W. Zhou, Q. Fan, Q. Zhang, L. Cai, K. Li, X. Gu, F. Yang, N. Zhang, Y. Wang, H. Liu, W. Zhou, S. Xie, High-performance and compact-designed flexible thermoelectric modules enabled by a reticulate carbon nanotube architecture, Nat. Commun., 2017, 8, 14886.

[9] S. Huang, Y. Liu, Y. Zhao, Z. Ren, C. F. Guo, Flexible electronics: stretchable electrodes and their future, Adv. Funct. Mater., 2018, 29, 1805924.

[10] S. W. Finefrock, X. Q. Zhu, Y. M. Suna, Y. Wu, Flexible prototype thermoelectric devices based on $\mathrm{Ag}_{2} \mathrm{Te}$ and PEDOT:PSS coated nylon fibre, Nanoscale, 2015, 7, 5598.

[11] E. W. Zaia, A. Sahu, P. Zhou, M. P. Gordon, J. D. Forster, S. Aloni, Y. S. Liu, J. H. Guo, J. J. Urban, Carrier scattering at alloy nanointerfaces enhances power factor in PEDOT:PSS hybrid thermoelectrics, Nano Lett., 2016, 16, 3352.

[12] C. L. Wan, X. K. Gu, F. Dang, T. Itoh, Y. F. Wang, H. Sasaki, M. Kondo, K. Koga, K. Yabuki, G. J. Snyder, R. Yang, K. Koumoto, Flexible n-type thermoelectric materials by organic 
intercalation of layered transition metal dichalcogenide $\mathrm{TiS}_{2}$, Nat. Mater., 2015, 14, 622.

[13] Y. Peng, S. J. Zhu, H. J. Lai, J. Gao, M. Kurosawa, O. Nakatsuka, S. Tanemura, B. Peng, L. Miao, No external load measurement strategy for micro thermoelectric generator based on high-performance $\mathrm{Si}_{1-\mathrm{x}-\mathrm{y}} \mathrm{Ge}_{\mathrm{x}} \mathrm{Sn}_{\mathrm{y}}$ film, J. Materiomics, 2020, doi.org/10.1016/j.jmat.2020.12.002.

[14] Y. Peng, H. J. Lai, C. Y. Liu, J. Gao, M. Kurosawa, O. Nakatsuka, T. Takeuchi, S. Zaima, S. Tanemura, L. Miao, Realizing high thermoelectric performance in p-type $\mathrm{Si}_{1-\mathrm{x}-\mathrm{y}} \mathrm{Ge}_{\mathrm{x}} \mathrm{Sn}_{\mathrm{y}}$ thin films at ambient temperature by Sn modulation doping, Appl. Phys. Lett., 2020, 117, 053903.

[15] W. Y. Zhao, S. F. Fan, N. Xiao, D. Y. Liu, Y. Y. Tay, C. Yu, D. H. Sim, H. H. Hng, Q. C. Zhang, F. Boey, J. Ma, X. B. Zhao, H. Zhang, Q. Y. Yan, Flexible carbon nanotube papers with improved thermoelectric properties, Energy Environ. Sci., 2012, 5, 5364.

[16] Z. Fan, D. Du, X. Guan, J. Ouyang, Polymer films with ultrahigh thermoelectric properties arising from significant seebeck coefficient enhancement by ion accumulation on surface, Nano Energy, 2018, 51, 481.

[17] Q. Jin, W. Shi, Y. Zhao, J. Qiao, J. Qiu, C. Sun, H. Lei, K. Tai, X. Jiang, Cellulose Fiber-based Hierarchical Porous Bismuth Telluride for High-performance Flexible and Tailorable Thermoelectrics, ACS Appl. Mater. Inter., 2018, 10, 1743.

[18] Z. Y. Huang, H. Zhang, L. Yang, B. Zhu, K. Zheng, M. Hong, Y. Yu, F. Q. Zu, J. Zou,Z. G. Chen, Achieving high thermoelectric performance of $\mathrm{Ni} / \mathrm{Cu}$ modified $\mathrm{Bi}_{0.5} \mathrm{Sb}_{1.5} \mathrm{Te}_{3}$ composites by a facile electroless plating, Mater. Today Energy, 2018, 9: 383.

[19] J. Gao, L. Miao, C. Liu, X. Wang, Y. Peng, X. Wei, J. Zhou, Y. Chen, R. Hashimoto, T. Asaka, K. Koumoto, A novel glass-fiber-aided cold-press method for fabrication of n-type $\mathrm{Ag}_{2} \mathrm{Te}$ nanowires thermoelectric film on flexible copy-paper substrate, J. Mater. Chem. A, 2017, 5, 24740.

[20] J. Gao, L. Miao, H. Lai, S. Zhu, Y. Peng, X. Wang, Thermoelectric flexible silver selenide films: compositional and length optimization, iScience, 2020, 23, 100753.

[21] Y. X. Chen, X. L. Shi, Z. H. Zheng, F. Li, W. D. Liu, W. Y. Chen, X. R. Li, G. X. Liang, J. T. Luo, P. Fan, Z. G. Chen, Two-dimensional $\mathrm{WSe}_{2} / \mathrm{SnSe}$ p-n junctions secure ultrahigh thermoelectric performance in n-type $\mathrm{Pb} / \mathrm{I}$ Co-doped polycrystalline SnSe, Mater. Today Phys., $2021,16,100306$. 
[22] J. M. Li, Ming, H. W. Ming, Song, C. J. Song, L. Wang, H. X. Xin, Y. J. Gu, J. Zhang, X. Y.

Qin, D. Li, Synergetic modulation of power factor and thermal conductivity for $\mathrm{Cu}_{3} \mathrm{SbSe}_{4}$-based system, Mater. Today Energy, 2020, 18: 100491.

[23] L. D. Zhao, S. H. Lo, Y. Zhang, H. Sun, G. Tan, C. Uher, C. Wolverton, V. P. Dravid, M. G. Kanatzidis, Ultralow thermal conductivity and high thermoelectric figure of merit in SnSe crystals, Nature, 2014, 508, 373.

[24] P. Fan, X. L. Huang, T. B. Chen, F. Li, Y. X. Chen, B. Jabar, S. Chen, H. L. Ma, G. X. Liang, J. T. Luo, X. H. Zhang, Z. H. Zheng, $\alpha$-Cu2Se thermoelectric thin films prepared by copper sputtering into selenium precursor layers, Chem. Eng. J., 2021, 410, 128444.

[25] H. L. Liu, X. Shi, F. F. Xu, L. L. Zhang, W. Q. Zhang, L. D. Chen, Q. Li, C. Uher, T. Day, G. J. Snyder, Copper ion liquid-like thermoelectrics, Nat. Mater., 2012, 11, 422.

[26] W. D. Liu, L. Yang, Z. G. Chen, $\mathrm{Cu}_{2} \mathrm{Se}$ thermoelectrics: property, methodology, and device, Nano Today, 2020, 35, 100938.

[27] Z. Y. Lin, Q. Y. He, A. X. Yin, Y. X. Xu, C. Wang, M. N. Ding, H. C. Cheng, B. J. Papandrea, Y. Huang, X. F. Duan, Cosolvent approach for solution-processable electronic thin films, ACS Nano, 2015, 9, 4398.

[28] Z. Y. Lin, C. Hollar, J. S. Kang, A. Yin, Y. L. Wang, H. Y. Shiu, Y. Huang, Y. J. Hu, Y. L. Zhang, X. F. Duan, A solution processable high-performance thermoelectric copper selenide thin film, Adv. Mater., 2017, 29, 1606662.

[29] M. R. Scimeca, F. Yang, E. Zaia, N. Chen, P. Zhao, M. P. Gordon, J. D. Forster, Y. S. Liu, J. H. Guo, J. J. Urban, A. Sahu, Rapid stoichiometry control in $\mathrm{Cu}_{2} \mathrm{Se}$ thin films for room-temperature power factor improvement, ACS Appl. Energy Mater., 2019, 2, 1517.

[30] J. D. Forster, J. J. Lynch, N. E. Coates, J. Liu, H. Jang, E. Zaia, M. P. Gordon, M. Szybowski, A. Sahu, D. G. Cahill, J. J. Urban, Solution-Processed $\mathrm{Cu}_{2} \mathrm{Se}$ Nanocrystal Films with Bulk-Like Thermoelectric Performance, Scientific Reports, 2017, 7, 2765.

[31] M. Q. Yang, Z. W. Shen, X. Q. Liu, W. Wang, Electrodeposition and thermoelectric properties of Cu-Se binary compound films, J. Electron. Mater., 2016, 45, 1974.

[32] Y. H. Lv, J. K. Chen, R. K. Zheng, X. Shi, J. Q. Song, T. S. Zhang, X. M. Li, L. D. Chen, (001)-oriented $\mathrm{Cu}_{2-y} \mathrm{Se}$ thin films with tunable thermoelectric performances grown by pulsed laser 
deposition, Ceram. Int., 2015, 41, 7439.

[33] K. S. Urmila, T. N. Asokan, R. R. Philip, V. Ganesan, G. S. Okram, B. Pradeep, Structural, optical, electrical and low temperature thermoelectric properties of degenerate polycrystalline $\mathrm{Cu}_{7} \mathrm{Se}_{4}$ thin films, Phys. Status Solidi B, 2014, 251, 689.

[34] A. Ghosh, C. Kulsi, D. Banerjee, A. Mondal, A. Ghosh, C. Kulsi, D. Banerjee, A. Mondal, Galvanic synthesis of $\mathrm{Cu}_{2-\mathrm{x}} \mathrm{Se}$ thin films and their photocatalytic and thermoelectric properties, Appl. Sur. Sci., 2016, 369, 525.

[35] U. Holzwarth, N. Gibson The Scherrer equation versus the 'Debye-Scherrer equation', Nat. Nanotechnol., 2011, 6, 534.

[36] L. Zhu, H. Xie, Y. Liu, D. Chen, Mingyang Bian a, Wenjun Zheng Novel ultralong hollow hyperbranched $\mathrm{Cu}_{2-\mathrm{x}} \mathrm{Se}$ with nanosheets hierarchical structure: Preparation, formation mechanism and properties, J. Alloys Compd., 2019, 802, 430.

[37] J. A. Perez-Taborda, L. Vera, O. Caballero-Calero, E. O. Lopez, J. J. Romero, D. G. Stroppa, F. Briones, M. Martin-Gonzalez, Pulsed hybrid reactive magnetron sputtering for high $\mathrm{ZT} \mathrm{Cu}_{2} \mathrm{Se}$ thermoelectric films, Adv. Mater. Technol., 2017, 2, 1700012.

[38] H. L. Liu, X. Yuan, P. Lu, X. Shi, F. F. Xu, Y. He, Y. Tang, S. Q. Bai, W. Q. Zhang, L. D. Chen, Y. Lin , L. Shi , H. Lin, X. Y. Gao, X. M. Zhang, H. Chi, C. Uher, Ultrahigh thermoelectric performance by electron and phonon critical scattering in $\mathrm{Cu}_{2} \mathrm{Se}_{1-\mathrm{x}} \mathrm{I}$, Adv. Mater., 2013, 25, 6607.

[39] A. Ghosh, C. Kulsi, D. Banerjee, A. Mondal, Galvanic Synthesis of $\mathrm{Cu}_{2-\mathrm{X}} \mathrm{Se}$ Thin Films and Their Photocatalytic and Thermoelectric Properties, Appl. Surf. Sci., 2016, 369, 525.

[40] L. Yang, Z. G. Chen, G. Han, M. Hong, J. Zou, Impacts of Cu defificiency on the thermoelectric properties of $\mathrm{Cu}_{2-\mathrm{X}} \mathrm{Se}$ nanoplates, Acta Materialia, 2016, 113, 140.

[41] X. X. Xiao, W. J. Xie, X. F. Tang, Q. J. Zhang, Phase transition and high temperature thermoelectric properties of copper selenide $\mathrm{Cu}_{2-\mathrm{x}} \mathrm{Se}(0 \leq \mathrm{x} \leq 0.25)$, Chin. Phys. B, 2011, 20, 087201.

[42] W. W. Liao, L. Yang, J. Chen, D. L. Zhou, X. L. Qu, K. Zheng, G. Han, J. B. Zhou, M. Hong, Z. G. Chen, Realizing Bi-doped $\alpha-\mathrm{Cu}_{2} \mathrm{Se}$ as a promising near-room-temperature thermoelectric material, Chem. Eng. J., 2019, 371, 593.

[43] H. L. Liu, X. Yuan, P. Lu, X. Shi, F. F. Xu, Y. He, Y. Tang, S. Q. Bai, W. Q. Zhang, L. D. 
Chen, Y. Lin , L. Shi , H. Lin, X. Y. Gao, X. M. Zhang, H. Chi, C. Uher, Ultrahigh thermoelectric performance by electron and phonon critical scattering in $\mathrm{Cu}_{2} \mathrm{Se}_{1-\mathrm{x}} \mathrm{I}$, Adv. Mater., 2013, 25, 6607. [44] J. Choi , J. Y. Lee, S. Lee, C. R. Park , H. Kim, High-Performance Thermoelectric Paper Based on Double Carrier-Filtering Processes at Nanowire Heterojunctions, Adv. Energy Mater., 2016, 6, 1502181.

[45] Y. Lu, Y. F. Ding, Y. Qiu, K. F. Cai, Q. Yao, H. J. Song, L. Tong, J. Q. He, L. D. Chen, Good performance and flexible PEDOT:PSS/ $\mathrm{Cu}_{2} \mathrm{Se}$ nanowire thermoelectric composite films, ACS Appl. Mater. Interfaces, 2019, 11, 12819.

[46] Y. F. Ding, Y. Qiu, K. F. Cai, Q. Yao, S. Chen, L. D. Chen, J. Q. He, High performance n-type $\mathrm{Ag}_{2} \mathrm{Se}$ film on nylon membrane for flexible thermoelectric power generator, Nature Communications, 2019, 10, 841.

[47] H. J. Shang, T. G. Li, D. Luo, L. Yu, Q. Zou, D. X. Huang, L. Y. Xiao, H. W. Gu, Z. F. Ren, F. Z. Ding, High-performance Ag-modified $\mathrm{Bi}_{0.5} \mathrm{Sb}_{1.5} \mathrm{Te}_{3}$ films for the flexible thermoelectric generator, ACS Applied Materials \& Interfaces, 2020, 12, 7358.

Table 1 Composition content of the $\mathrm{Cu}$-Se thin film as function of Se layer thickness

\begin{tabular}{ccccccc}
\hline Se layer thickness (nm) & 70 & 80 & 90 & 100 & 110 & 120 \\
\hline $\mathrm{Cu}($ at.\%) & 69.9 & 68.3 & 67.6 & 66.3 & 65.6 & 65.0 \\
Se (at.\%) & 30.1 & 31.7 & 32.4 & 33.7 & 34.4 & 35.0 \\
$\mathrm{Cu}: \mathrm{Se}$ & $2.32: 1$ & $2.15: 1$ & $2.09: 1$ & $1.97: 1$ & $1.91: 1$ & $1.86: 1$ \\
\hline
\end{tabular}

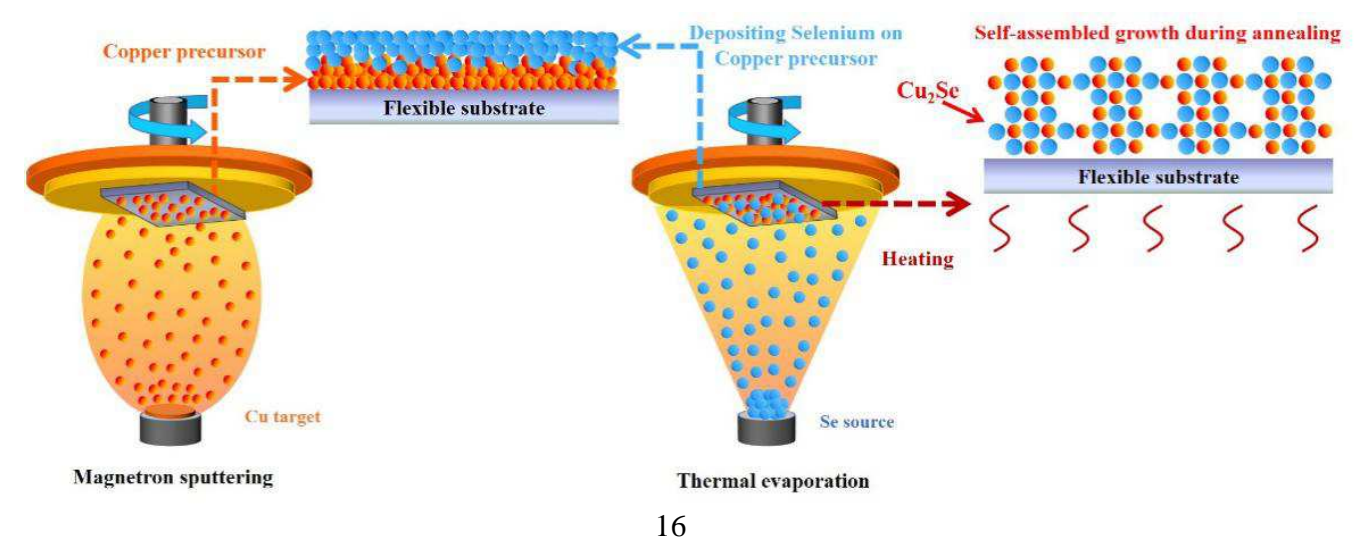


Fig. 1. The schematic diagram of fabricating the $\mathrm{Cu}_{2} \mathrm{Se}$ thin film

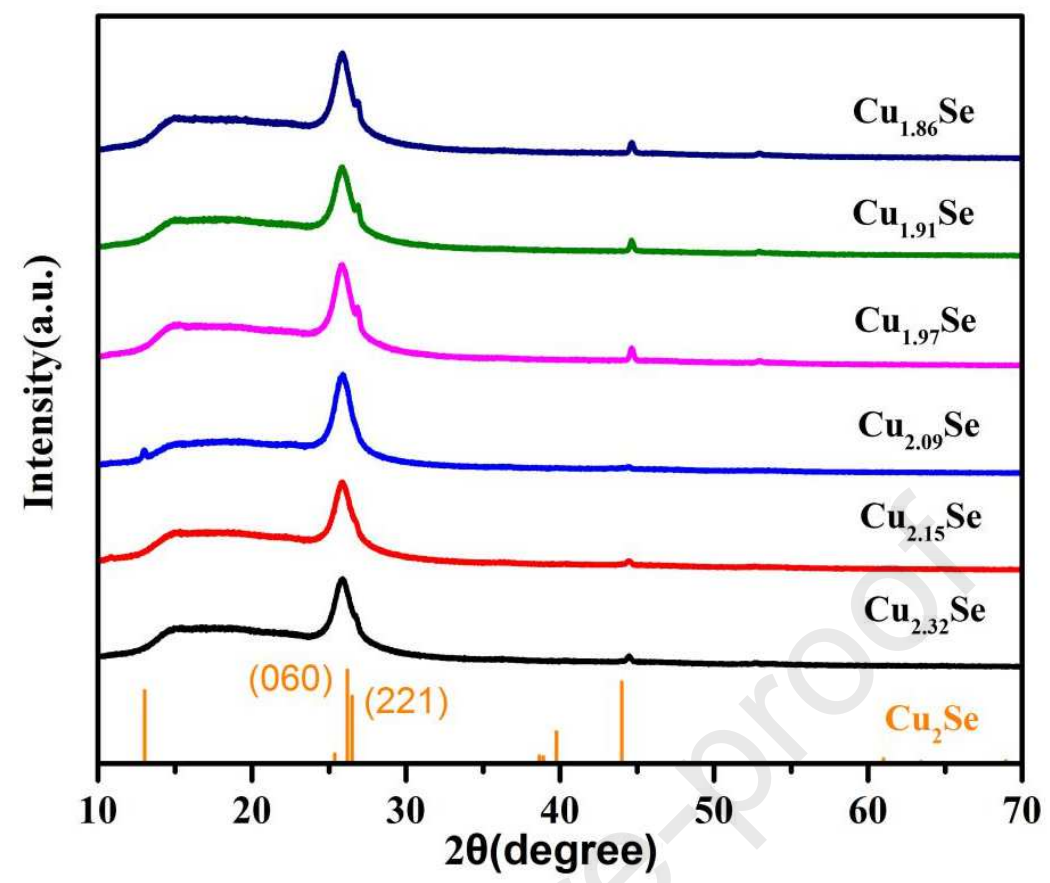

Fig. 2 XRD data of flexible $\mathrm{Cu}_{2} \mathrm{Se}$ thin films with different composition ratios
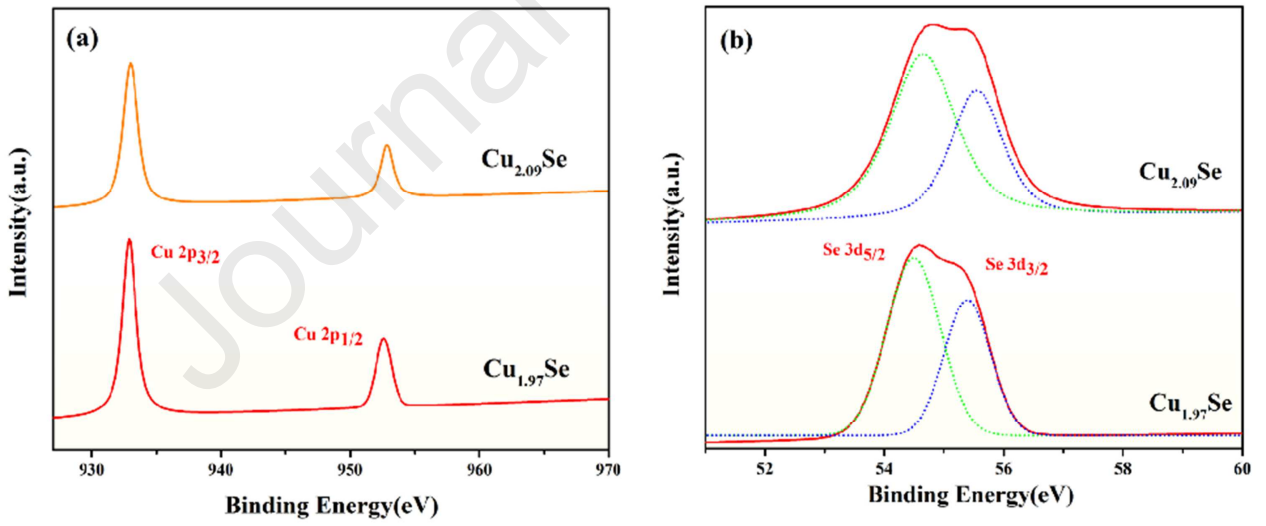

Fig. 3 XPS data of flexible $\mathrm{Cu}_{2}$ Se thin films with a composition ratio of the 1.97:1 and 2.09:1, (a) $\mathrm{Cu}$; (b) $\mathrm{Se}$ 


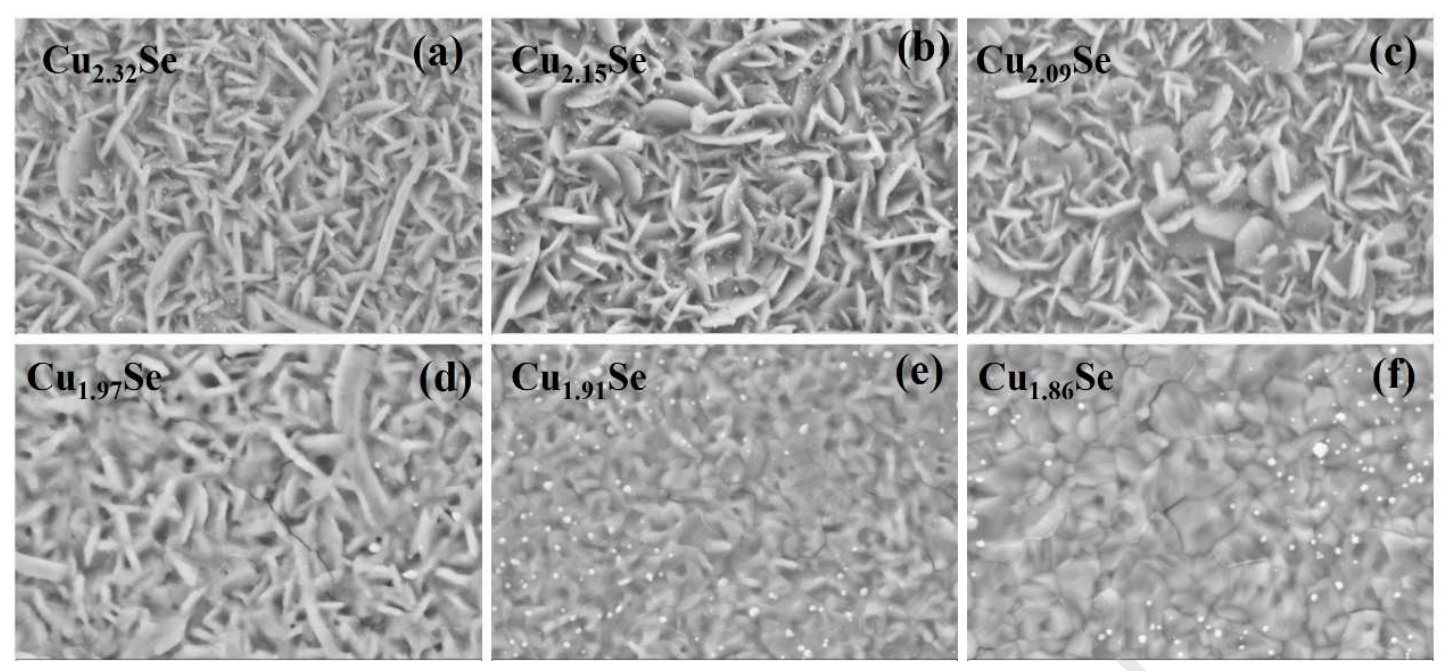

Fig. 4 SEM images of flexible $\mathrm{Cu}_{2} \mathrm{Se}$ thin films with different composition ratio (a)

$\mathrm{Cu}_{2.32} \mathrm{Se}$; (b) $\mathrm{Cu}_{2.15} \mathrm{Se}$; (c) $\mathrm{Cu}_{2.09} \mathrm{Se}$; (d) $\mathrm{Cu}_{1.97} \mathrm{Se}$; (e) $\mathrm{Cu}_{1.91} \mathrm{Se}$; (f) $\mathrm{Cu}_{1.86} \mathrm{Se}$ 

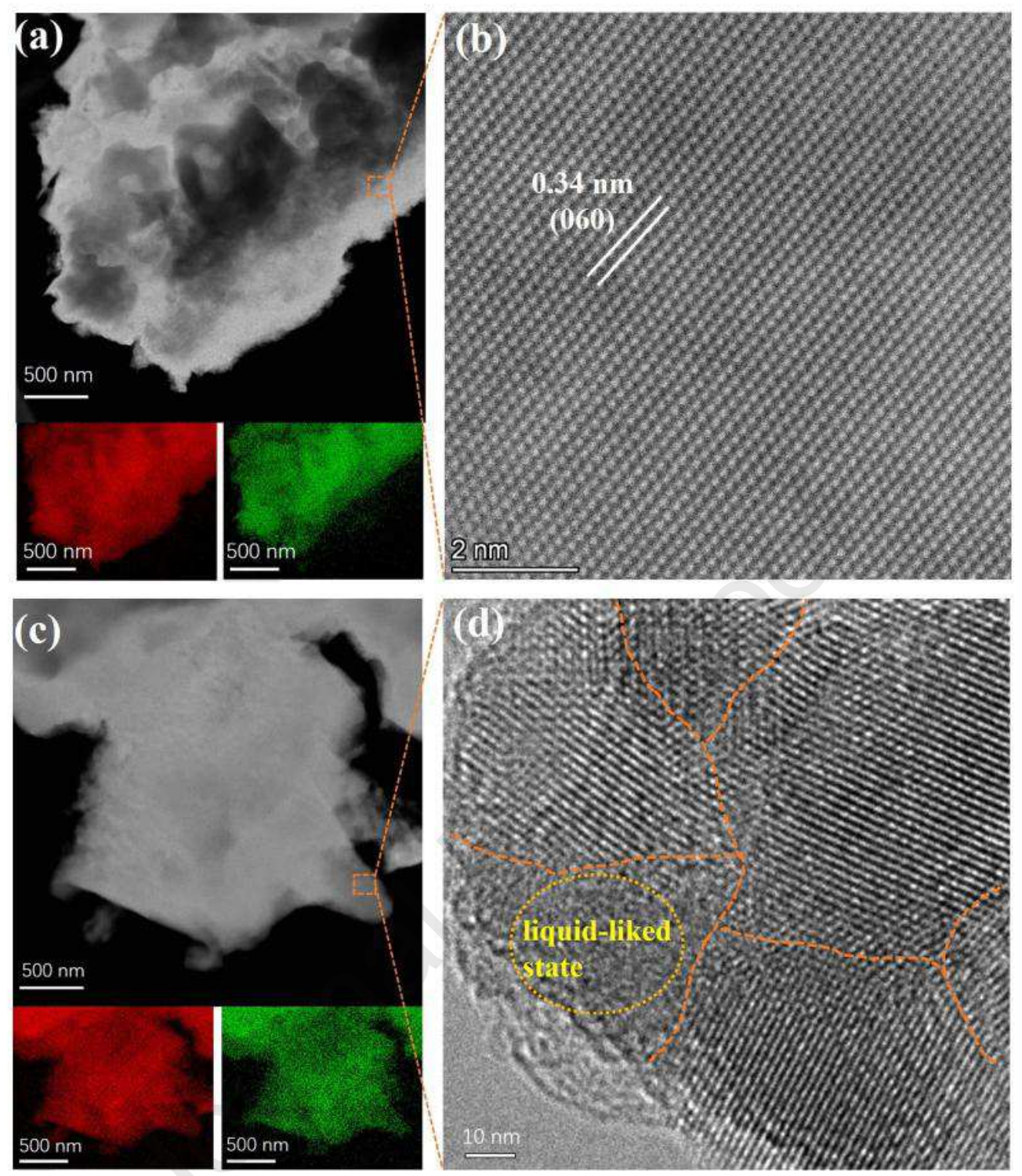

Fig. 5 (a) TEM characterization and EDS elemental mappings of the $\mathrm{Cu}_{1.97} \mathrm{Se}$ thin

film. (b) Lattice fringes in (a) performed by HRTEM. (c) TEM characterization and EDS elemental mappings of the $\mathrm{Cu}_{2.09}$ Se thin film. (d) Lattice fringes in (c) performed by HRTEM. 

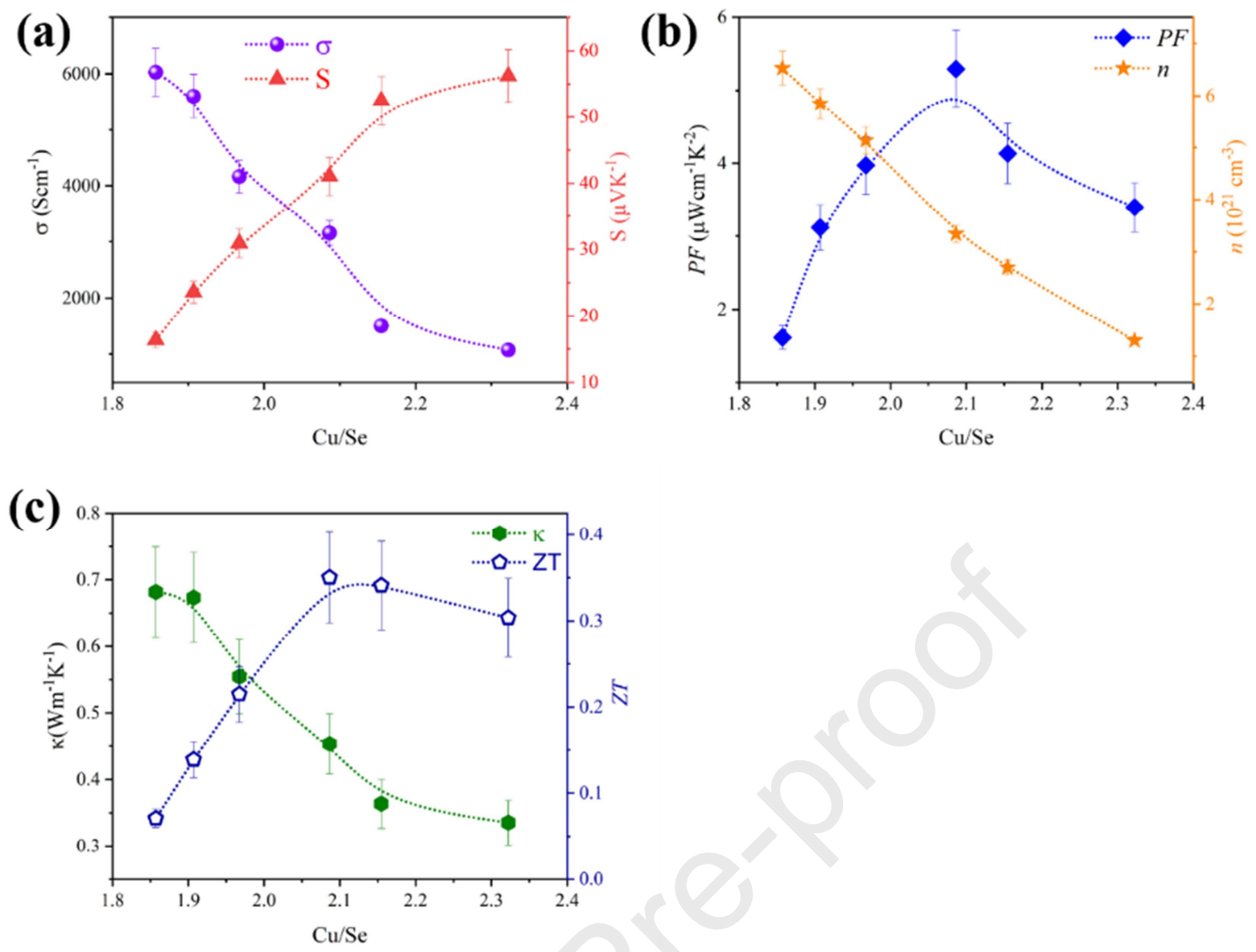

Fig. 6 The thermoelectric properties of flexible $\mathrm{Cu}_{2} \mathrm{Se}$ thin films as function of atomic ratios (a) electrical conductivity and Seebeck coefficient; (b) Power factor and carrier concentration; (c) thermal conductivity and $Z T$ 
(a)

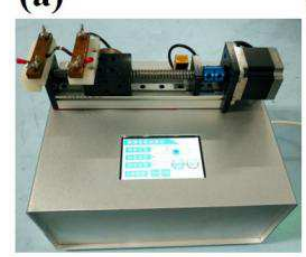

(b)

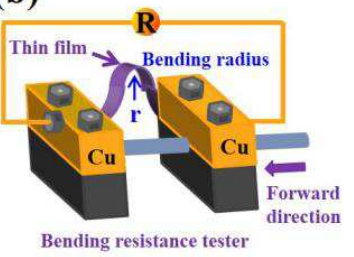

(d)
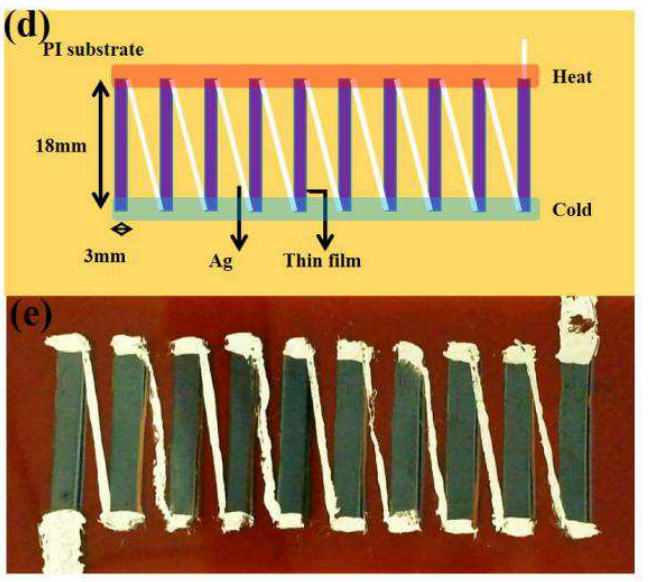

(c)
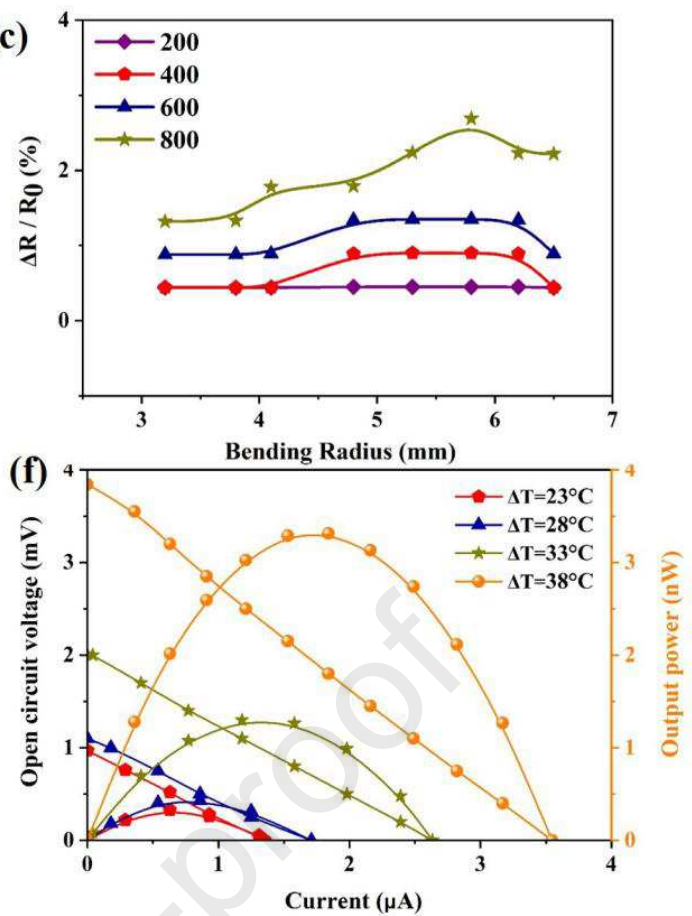

Fig. 7. (a) Optical image and (b) the schematic diagram of the bending system. (c) the influence of bending cycle and bending radius on the resistance difference of the $\mathrm{Cu}_{2.09}$ Se thin film. (d) the structure diagram and (e) optical image of the fabricated device. (f) open voltage and output power as function of current of the device. 


\section{Highlights}

(1) layer-by-layer combination reaction method for preparing high-performance $\mathrm{Cu}_{2} \mathrm{Se}$ thin films.

(2) The self-assembled growth of $\mathrm{Cu}_{2} \mathrm{Se}$ with single crystal phase were successfully fabricated.

(3) High power factor of $5.3 \mu \mathrm{Wcm}^{-1} \mathrm{~K}^{-2}$ and $Z T$ value of 0.35 are achieved at room-temperature.

(4) Thin film possesses well flexibility and the designed flexible device displays stable out-put power. 


\section{Declaration of interest statement}

The authors declare that they have no known competing financial interests or personal relationships that could have appeared to influence the work reported in this paper. 